3-11-2020

\title{
The community health system in Bangladesh: An overview
}

Frontline Health Project

Follow this and additional works at: https://knowledgecommons.popcouncil.org/departments_sbsr-rh

Part of the Community Health and Preventive Medicine Commons, Demography, Population, and Ecology Commons, Family, Life Course, and Society Commons, International Public Health Commons, Medicine and Health Commons, and the Women's Health Commons How does access to this work benefit you? Let us know!

\section{Recommended Citation}

Frontline Health Project. 2020. "The community health system in Bangladesh: An overview," brief. Washington, DC: Population Council. 


\section{The Community Health System in Bangladesh: An Overview}

\section{BANGLADESH HEALTH SYSTEM}

Bangladesh is divided into eight administrative divisions, 64 districts, and 545 sub-districts, known as upazilas (formerly referred to as thanas) (1). Each rural area within an upazila is divided into union parishads and mouzas, which are further divided into villages (1).

The Ministry of Health and Family Welfare (MOHFW) has an extensive health infrastructure that is pluralistic and follows the country's administrative pattern. Union parishads are the smallest administrative unit in rural areas. At the lowest administrative level, traditional healers, non-qualified allopathic practitioners, and community health workers (CHWs) are typically the only providers available (2). The different administrative levels, their governance, and associated health facilities are detailed in Figure 1.

\section{COMMUNITY HEALTH WORKER STRATEGY}

In September 2019, the MOHFW endorsed the proposed Bangladesh Strategy for Community Health Workers (2019-2030). Save the Children in Bangladesh led the strategy's development, and a consortium of community health stakeholders provided input. The objectives of the strategy are three-fold: Provide guidance and a framework for selection, training, certification, recruitment, and deployment of CHWs; strengthen the management and supervision structure of CHWs; and establish systems for $\mathrm{CHW}$ integration into and support by health systems and communities (3).

The strategy provides guidelines for CHWs' selection, certification, capacity building, linkages with primary health structures, supervision and monitoring, and improving performance. A national action plan is underway for implementation of the strategy (3).

\section{Figure 1. Bangladesh Health System Structure}

\section{Administrative level (n) \\ National/Division (8)

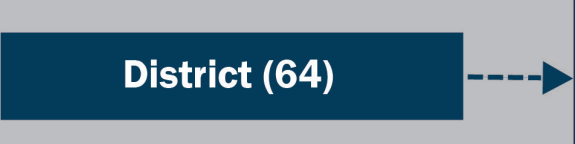 programs, and activities. The DGHS and DGFP are executive agencies within the MOHFW that implement health programs. \\ A health administrator in each district provides management and oversight, and serves as a link between the national and upazila levels.}

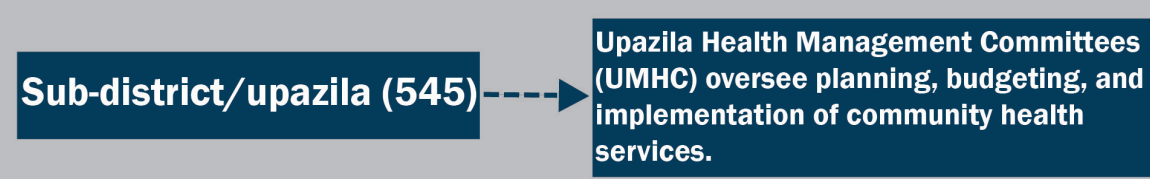

services.
Associated health facilities/ structures

Specialized hospitals and Medical College hospitals

District hospitals, Mother and Child Welfare Centers, Medical College hospitals

Upazila Health Complexes (UHCs)

Union Health and Family

Medical Officers (SACMOS), and Family Welfare Volunteers (FWVs) are based at Union Health and Family Welfare Centers (UHFWCs) and visit and support community clinics at the ward level.

Community groups (CGs) comprised of

13-17 community members are

responsible for running community clinics. Community support groups (CSGS) provide further support to the CGs in their oversight. CHCPs, FWAs, and HAs provide services at community clinics.

Ward/Village $(87,223)$ 
The Bangladesh Strategy for Community Health Workers (2019-2030) is cited by the MOHFW as a complementary document of the Bangladesh National Health Workforce Strategy (BNHWS) which was deployed in 2015. The health workforce strategy focuses on five major areas related to the health workforce: planning, capacity development, recruitment, performance management, and information systems (3).

\section{GOVERNMENT COMMUNITY HEALTH WORKER PROGRAMS * IN BANGLADESH}

Currently active $\mathrm{CHWs}$ in Bangladesh are employed by the MOHFW or local non-governmental organizations (NGOs) (3). CHWs employed by the MOHFW at the union, ward, and village levels are divided into three categories: Health Assistants (HAs) that fall under the Directorate General of Health Services (DGHS), Family Welfare Assistants (FWAs) that fall under the Directorate General of Family Planning (DGFP), and Community Health Care Providers (CHCPs) that are based at community clinics (CCs) and fall under the purview of DGHS.

CCs operate at the village level in the health system, and are regarded by the MOHFW as the first contact point for essential health services. There is approximately one CC for every 6,000 people in Bangladesh
Ideally, the location of each CC is set so that at least $80 \%$ of the population it serves is able to reach the clinic in a 30-minute walk (4).

The profiles of FWAs, HAs, and CHCPs are distinct. FWAs were introduced by the government in 1976, and their work focuses on family planning provision and referral for clients for antenatal and postnatal care (ANC and PNC). HAs were introduced as a formal $\mathrm{CHW}$ cadre in 1995, with added responsibilities over the years. Prior to being recognized as a formal cadre, many HAs were working as vaccinators or malaria control workers. Their work was expanded to focus on immunizations, Vitamin A supplementation, and detection and treatment of pneumonia, diarrhea, malaria, and tuberculosis. CHCPs were introduced in 2010 to staff CCs. Their main responsibilities are to provide ANC and PNC, treat cases of pneumonia, diarrhea, and anemia, and provide family planning, mainly in the form of providing second doses of injectable contraception (4).

Traditionally, HAs and FWAs provided services solely at the household level and through outreach clinics, however, a recent government directive stipulated that they are stationed alongside CHCPs at CCs to provide services for three days a week in addition to continuing their household visits (4). More information about FWAs, HAs, and CHCPs is shown in Figure 2.

(3).

\section{Figure 2: Characteristics of Community Health Care Providers (CHCPs), Health Assistants (HAs), and Family Welfare Assistants (FWAs) in Bangladesh}

Access to Clients

CHCPs provide services solely at community clinics, while FWAs and HAs access clients on foot, by bicycle, or clients travel to community clinics to see them.

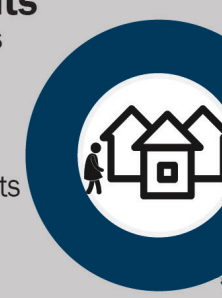

\section{Selection Process}

CHCPs, FWAs, and HAs are recruited at the national level, with some selection done at the district level. FWAs are required to be female, while HAs and CHCPs can be either female or male. All cadres must have at least 10 years of schooling.

must

\section{Link to Health System}

CHCPs, FWAs, and HAs are all employed by the MOHFW, and provide services at governmentrun community clinics and via household outreach.
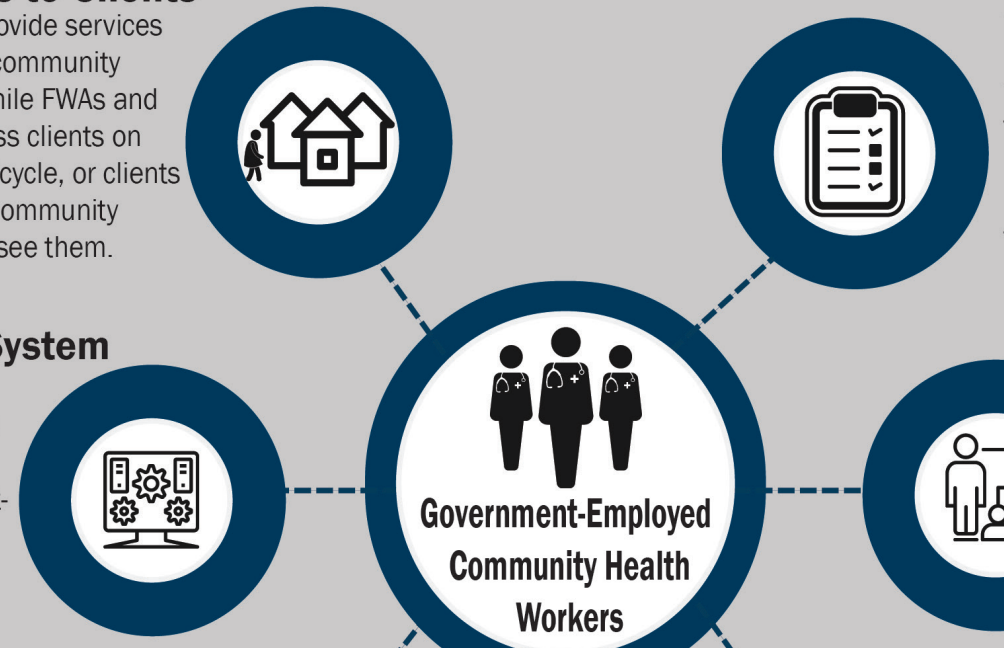

\section{Supervision} FWAs are supervised by male supervisors with whom they meet twice per month. HAs and CHCPs are supervised by assistant health inspectors.

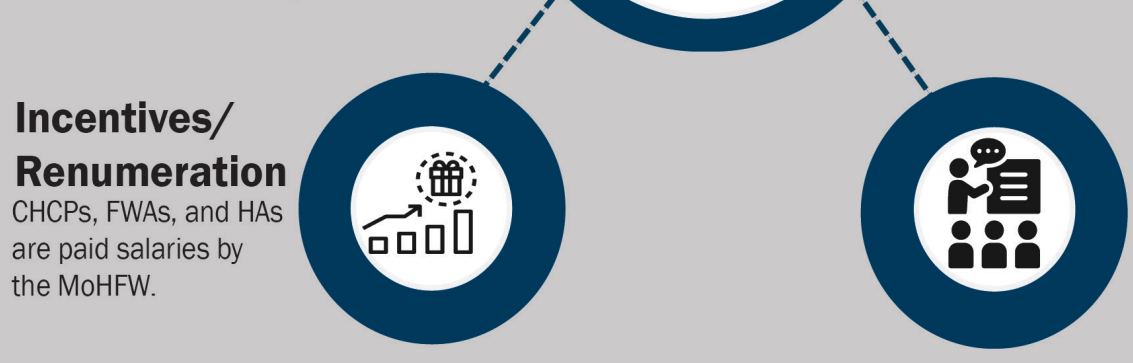

\section{Training}

- CHCPs undergo an initial basic training for 12 weeks, with refresher trainings conducted as needed. - FWAs and HAs undergo an initial 21-day training followed by on-the job training. 


\section{NON-GOVERNMENT COMMUNITY HEALTH WORKER PROGRAMS IN BANGLADESH}

The profiles of CHWs working for different NGOs are distinct, with different names, designations, selection criteria, job requirements, and renumeration. This brief will focus on the largest NGO employer of CHWs in Bangladesh--BRAC--which is also the largest NGO in the world, and operates in nine countries. In Bangladesh, there are an estimated $100,000 \mathrm{CHWs}$ employed by BRAC (2).

BRAC began CHW programming in the early 1970s by adopting the Barefoot Doctor approach first used in China and applying it to male paramedics. In the early 1980s, BRAC shifted its focus to lesser-trained female $\mathrm{CHWs}$ who were familiar with health promotion and disease prevention, and began the Shasthya Shebika (SS) Program. Shasthya Shebikas (SSs) conduct monthly household visits and provide health education to families on topics including nutrition, safe delivery, family planning, immunizations, and water, sanitation, and hygiene (WASH). They also provide referrals to government health centers and BRAC clinics. SSs work parttime in the afternoons, and receive no salary. They sell health commodities such as soap, sanitary napkins, and basic medicine to generate a small profit in order to sustain their work (4).

SSs are supervised by Shasthya Kormis (SKs), higher-level CHWs which receive a monthly salary. In 2008, BRAC introduced Newborn Health Workers (NHWs) and Community Skilled Birth Attendants (CSBAs) as additional cadres of CHWs to improve maternal, neonatal, and child survival services. NHWs and CSBAs are responsible for providing newborn follow-up and care and providing skilled births within the community, respectively. All together, SSs, SKs, NHWs, and CSBAs provide a range of services to pregnant mothers, neonates, and children under five (4).

\section{REFERENCES}

1. Ministry of Planning. 2014. Bangladesh Population and Housing Census 2011: Union Statistics. Dhaka, Bangladesh: Government of Bangladesh.

2. Egan KF, Devlin K, and Pandit-Rajani T. 2017. Community Health Systems Catalog Country Profile: Bangladesh. Arlington, VA: Advancing Partners \& Communities.

3. Ministry of Health and Family Welfare. 2019. Bangladesh National Strategy for Community Health Workers (2019-2030). Dhaka, Bangladesh: Government of Bangladesh.

4. Perry H, Zullinger R, Scott K, et al. 2017. Case Studies of Large Scale Community Health Worker Programs. Washington, DC: Maternal and Child Health Integrated Program (MCHIP).

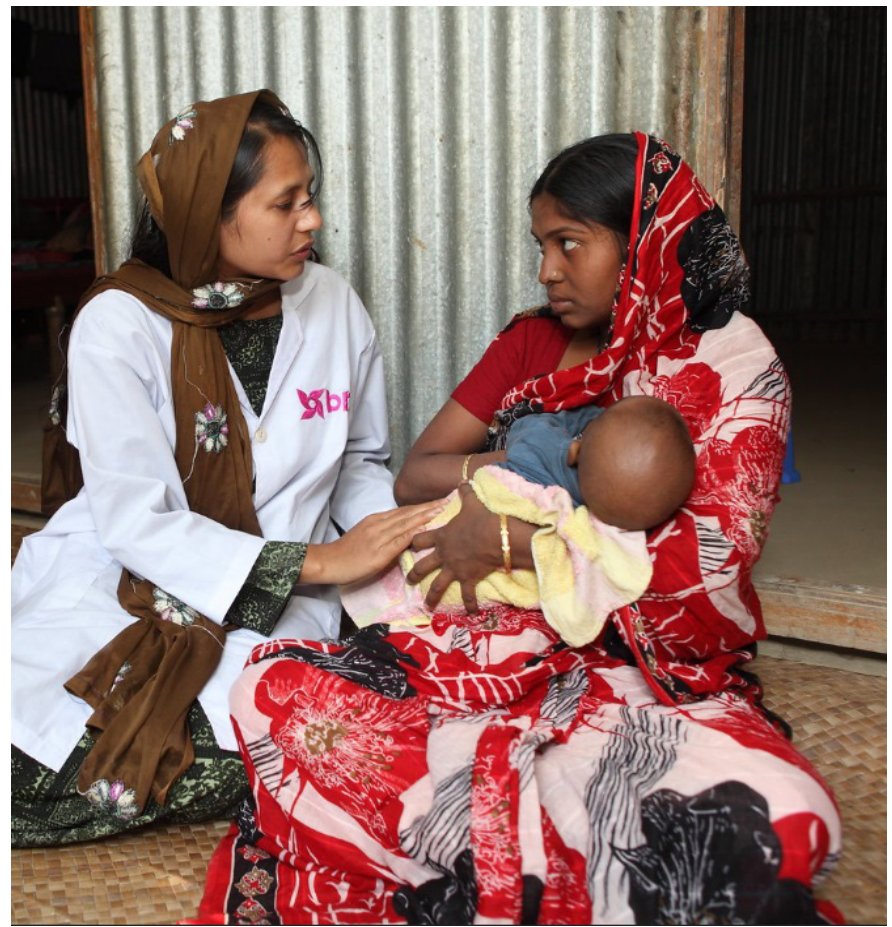

Photo credit: BRAC. 2013. An SS working under BRAC's Alive \& Thrive program counsels a mother on breastfeeding.

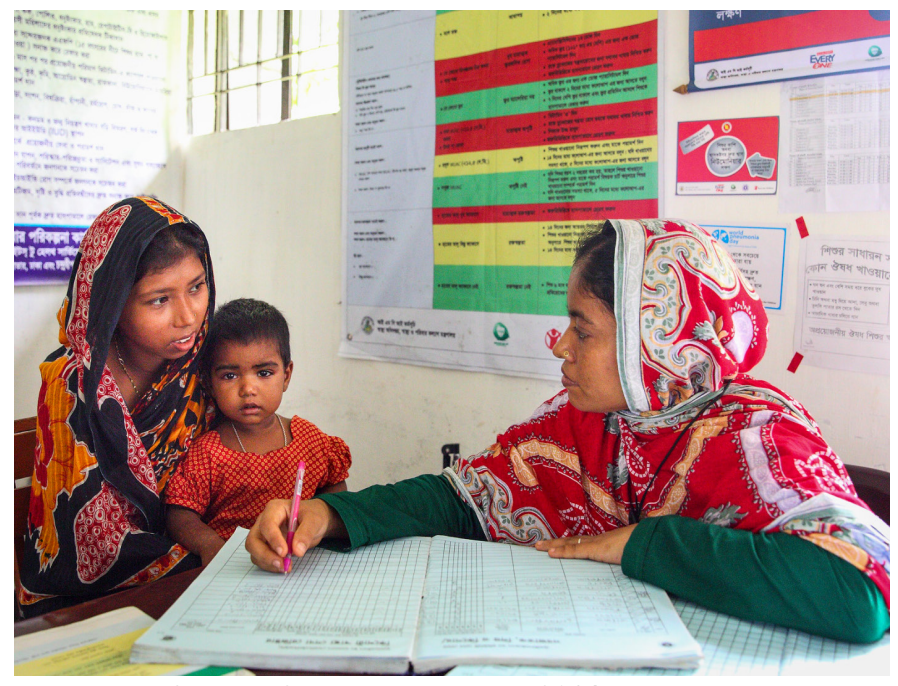

Photo credit: Save the Children Bangladesh. 2014. A mother is educated on nutrition by a health worker at a community clinic.

Suggested citation: Frontline Health Project. 2020. "The Community Health System in Bangladesh: Overview.” Washington, D.C.: Population Council.
The Frontline Health: Harmonizing Metrics, Advancing Evidence, Accelerating Policy project seeks to advance community health systems metrics, monitoring and learning to improve the efficiency and performance of community health worker programs.
The Population Council conducts research and delivers solutions that improve lives around the world. Big ideas supported by evidence: It's our model for global change. popcouncil.org 